\title{
Analysis of Seaweed Extract-induced Transcriptome Leads to Identification of a Negative Regulator of Salt Tolerance in Arabidopsis
}

\author{
Mundaya N. Jithesh ${ }^{1}$ and Owen S.D. Wally ${ }^{1}$ \\ Department of Environmental Sciences, Nova Scotia Agriculture College, P.O. Box 550, Truro, \\ Nova Scotia B2N5E3, Canada \\ Iain Manfield \\ Centre for Biomolecular Interactions, Astbury Centre for Structural Molecular Biology, \\ University of Leeds, United Kingdom \\ Alan T. Critchley and David Hiltz \\ Acadian Seaplants Limited, Dartmouth, 30 Brown Avenue, Dartmouth, Nova Scotia, B3B 1 X8 Canada \\ Balakrishnan Prithiviraj ${ }^{2}$ \\ Department of Environmental Sciences, Nova Scotia Agriculture College, P.O. Box 550, Truro, \\ Nova Scotia B2N5E3, Canada
}

Additional index words. Arabidopsis, Ascophyllum nodosum, pectin methylesterase inhibitor, salt tolerance

\begin{abstract}
Successful development of plants resistant to salinity stress is problematic as a result of the complex polygenic natures of salt tolerance. Previously, alkaline extracts of the brown seaweed Ascophyllum nodosum have shown promise in enhancing plant tolerance toward abiotic stresses. To understand the underlying molecular mechanisms, the whole genome transcriptome of Arabidopsis undergoing salt stress was analyzed by microarray analysis after treatment with the chemical components of $A$. nodosum extracts (ANE). Treatment with ANE induced many positive regulators of salt tolerance in addition to downregulating numerous other genes. Using T-DNA insertion mutants within these downregulated genes, we examined the potential for a novel source of enhanced $\mathrm{NaCl}$ tolerance through removal of negative regulators of $\mathrm{NaCl}$ stress responses within Arabidopsis. Several potential target mutations were identified with enhanced salt-tolerant phenotypes. A T-DNA insertion within the promoter of a putative Pectin Methyl Esterase Inhibitor (PMEI) gene (At1g62760) was found to be resistant to salinity stress and was further characterized. This T-DNA insertion mutant was designated as pmei1-1. The phenotype of pmeil-1 seedlings included increased primary root growth in vitro and improved biomass accumulation under $\mathrm{NaCl}$ stress. Additionally, modified transcript levels of dehydration-responsive genes, including $R D 29 A$, were observed in pmei1-1 plants. Taken together, these results suggest a role for PMEI as a negative regulator of $\mathrm{NaCl}$ resistance and that chemical stress-induced transcriptome analysis may lead to identification of additional novel regulators of abiotic stress tolerance in plants, the use of which would have significant implications for agriculture globally.
\end{abstract}

Plants are sessile organisms that are faced with a range of abiotic stresses throughout their lifespan, which are increasing on a global scale. High salinity is one of the major abiotic stress factors that significantly reduce crop yield and productivity. High $\mathrm{NaCl}$ conditions adversely affect plant growth through increased osmolarity, ion toxicity (i.e., $\mathrm{Na}^{+}$ $\mathrm{Cl}^{-}$, and $\left.\mathrm{SO}_{4}^{-}\right)$, nutritional imbalance, and oxidative stress (Turkan and Demiral, 2009). The main toxic effects of $\mathrm{Na}^{+}$include inhibition of enzyme activities and disruption of intracellular $\mathrm{K}^{+} / \mathrm{Na}^{+}$homeostasis (Zhu, 2002). To cope with high salinity, plants have developed a number of mechanisms, including altered gene expression pathways through hormone regulation

Received for publication 7 Nov. 2011. Accepted for publication 3 Jan. 2012.

This paper was part of the colloquium, "Emerging Techniques to Evaluate and Mitigate Crop Environmental Stress in a Changing Climate" held 28 Sept. 2011 at the ASHS Conference, Waikoloa, HI, and sponsored by the Environmental Stress Physiology (STRS) Working Group.

${ }^{1}$ Contributed equally to this work

${ }^{2}$ To whom reprint requests should be addressed; e-mail bprithiviraj@nsac.ca. for ion exclusion or decreasing water potential within the plant to cope with the added salts (Kronzucker and Britto, 2011). Molecular genetic approaches, aimed at dissecting the complexity of $\mathrm{NaCl}$ stress responses in plants, have provided new understanding to the biological processes involved in perception and signal transduction of environmental cues perceived by the plants (Sreenivasulu et al., 2007). Microarray studies established that plant response to $\mathrm{NaCl}$ involved subtle alterations in the expression of genes involved in oxidative, osmotic pathway, vacuolar antiporters (Seki et al., 2002; Taji et al., 2004), transcription regulators (Kreps et al., 2002), and cell wall-related genes (Walia et al., 2005).

Production of plants with superior agronomically important traits, including tolerance to high $\mathrm{NaCl}$ conditions, has been a focal theme of plant biotechnology. There have been numerous attempts to improve salinity tolerance in glycophilic plants that typically involved overexpression of genes, upregulated during stress conditions; including genes involved in production of compatible solutes, sodium exclusion, and reactive oxygen scavenging (reviewed in Arzani, 2008; Ashraf and Akram, 2009; Stamm et al., 2011; Wally et al., 2011). Recently research focused on growth promotion through increased cytokinin levels under the control of stress-induced promoters with varying levels of success (Havlova et al., 2008; Rivero et al., 2007, 2010). Although these logical biotechnological methods to improve abiotic stress tolerance continue to hold promise, novel functional genomics approaches to isolate genes for abiotic stress tolerance are required for further improvement in this field. In earlier studies, it was observed that addition of commercial extract from the brown macroalgae, ANE, induced salt stress and drought tolerance in plants (Nabati et al., 1994; Spann and Little, 2011). To understand the molecular basis of $A$. nodosum-elicited salt stress tolerance, microarray analysis was preformed. It was observed that the seaweed components elicited a genomewide transcriptional response by upregulating several known, positive regulators of $\mathrm{NaCl}$ tolerance (Prithiviraj et al., unpublished data). Additionally, there were many genes that were downregulated during $\mathrm{NaCl}$ stress on addition of ANE. Further functional phenotypic screening of Arabidopsis knockout mutants for some of the downregulated genes during salt stress were examined under the premise that these might represent new novel regulators involved for $\mathrm{NaCl}$ tolerance in plants. We present the screening of 18 
T-DNA knockout mutations of the downregulated genes with detailed characterization of one gene, Atlg62760, which encodes for a putative PMEI that exhibits heightened resistance toward salt stress.

\section{MATERIALS AND METHODS}

Salt resistance screening. The Arabidopsis Col-0 T-DNA insertional mutants from seaweed extract (To et al., 2007) transcriptome downregulated genes were obtained from the Arabidopsis Biological Resource Center stock center (Columbus, OH; Table 1). Rapid assessment of salt stress tolerance was conducted as previously described (Achard et al., 2006; Verslues et al., 2006); 4-day-old plants were grown on half-strength Murashige and Skoog (MS) medium (Sigma, St. Louis, MO) supplemented with $0.1 \%(\mathrm{w} / \mathrm{v})$ sucrose solidified with $0.8 \%(\mathrm{w} / \mathrm{v})$ agar and were transferred onto half-strength MS plates containing either 0 or $125 \mathrm{~mm} \mathrm{NaCl}$. The plates were then maintained in a growth chamber at $22^{\circ} \mathrm{C}$ with a 16-h light/8-h dark cycle with a light intensity of $100 \mu \mathrm{mol} \cdot \mathrm{m}^{-2} \cdot \mathrm{s}^{-1}$. Root elongation rates were measured at 3,5 , and $7 \mathrm{~d}$ after transfer, marking the progress of root growth at each time and measured with Image $\mathrm{J}$ software (Research Services Branch, National Institutes of Health, Bethesda, MD). Root elongation of the T-DNA lines was compared with the Col- 0 controls and analyzed using analysis of variance Tukey's honestly significant difference test $P<0.05$ with SPSS 15.0 software (Leads Technology).

Quantitative reverse transcriptionpolymerase chain reaction analysis. Total RNA was isolated using the monophasic RNA extraction method (Chomczynski and Sacchi, 1987). Two micrograms of RNA was treated with 2 units of RQ1 DNAse (Promega) according to the manufacturer's instructions. cDNA was synthesized using an Applied Biosystems high-capacity cDNA synthesis kit (Applied Biosystems) using the manufacturer's protocols. Relative transcript levels were assayed by real-time polymerase chain reaction (PCR) analysis using genespecific primers on a StepOne ${ }^{T M}$ Real-Time PCR System (Applied Biosystems) using SYBR gene reagent power SYBR (Applied Biosystems). Primer sequences were taken from the Roche Universal ProbeLibrary (Roche Diagnostics Corp.). Wherever possible, the primers would flank an intron-spanning region. All amplicon length ranges were between 68 and $120 \mathrm{bp}$. The reaction mixture contained $5 \mu \mathrm{L}$ of Power SYBR Green PCR Master Mix (Applied Biosystems), 20 ng of cDNA, and $250 \mathrm{nM}$ of each of the forward and reverse primers. The following default program was used: $95{ }^{\circ} \mathrm{C}$ for 10 min followed by 40 cycles of $95{ }^{\circ} \mathrm{C}$ for $15 \mathrm{~s}$ and $60{ }^{\circ} \mathrm{C}$ for $1 \mathrm{~min}$ each and a dissociation stage of $95^{\circ} \mathrm{C}$ for $15 \mathrm{~s}$, $60{ }^{\circ} \mathrm{C}$ for $30 \mathrm{~s}$, and $95{ }^{\circ} \mathrm{C}$ for $15 \mathrm{~s}$. RNA relative quantification analyses were performed using 7300 System SDS software (Applied Biosystems). The list of primers used is shown in Table 2. The data represent the mean $\pm \mathrm{SE}$ of $\mathrm{n}=3$ independent experiments using

Table 1. Initial screening of Arabidopsis T-DNA lines for increased salt resistance.

\begin{tabular}{llllc}
\hline & & Insertion & & $\begin{array}{c}\text { Increased } \\
\text { root length }\end{array}$ \\
Gene name & T-DNA line & location & Accession & - \\
Wall-Associated kinase 1 & Salk_107175 & Exon & AT1G21250 & - \\
Glycine-rich RNA binding protein & Salk_137260 & Promoter & AT1G21250 & - \\
Glycine-rich RNA binding protein & Salk_047963c & Exon & AT4G39260 & - \\
Glycine-rich RNA binding protein & Salk_114544 & Exon & AT4G39260 & + \\
Cellulose synthase like e1 & Salk_072106 & Promoter & AT4G39260 & - \\
Cellulose synthase like e1 & CS25016 & Exon & AT1G55850 & - \\
Cellulose synthase like e1 & Salk_123441 & Exon & AT4G24000 & - \\
Cellulose synthase like e1 & Salk_008597c & Exon & AT4G24000 & - \\
Pectin methylesterase inhibitor & Salk_072421 & Promoter & AT1G62760 & ++ \\
Pectin methylesterase inhibitor & Salk_007858c & Promoter & AT1G62760 & ++ \\
Pectin methylesterase inhibitor & Salk_084836c & Promoter & AT1G62760 & + \\
RNA binding protein & Salk_078245 & Exon & AT5G61030 & - \\
RNA binding protein & Salk_078241 & Exon & AT5G61030 & - \\
RNA binding protein & Salk_007592 & Exon & AT5G61030 & - \\
RNA binding protein & Salk_098675 & Exon & AT5G61030 & + \\
RNA binding protein & Salk_078146 & Intron & AT5G61030 & - \\
RNA binding protein & Salk_007455 & Promoter & AT5G61030 & - \\
\hline
\end{tabular}

Screening of T-DNA insertion mutants from genes identified from microarray downregulated during salt stress after application of organic fraction of $A$. nodosum seaweed extracts (B. Prithiviraj, unpublished data). Lines were assessed for increased root length, growing on half-strength Murashige and Skoog MS media supplemented with $125 \mathrm{~mm} \mathrm{NaCl}$. Lines were scored $(-)$ no increase, $(+) 10 \%$ increase in root length, or $(++)$ more than $20 \%$ increase compared with controls. Thirty seedlings were scored from two repeated experiments.

Table 2. Primers used for quantitative reverse transcription-polymerase chain reaction.

\begin{tabular}{llc}
\hline Primer & \multicolumn{1}{c}{ Sequence $\left(5^{\prime}-3^{\prime}\right)$} & Accession number \\
\hline Act2-F & ttgttgttcatttccettttg & AT3G18780 \\
Act2-R & gcagacgtaagtaaaaacccagaga & AT3G18780 \\
Pmei1-F & gcctccaaattcgtcaaaaa & AT1G62760 \\
Pmei1-R & cgcaactacttccaaacgtg & AT1G62760 \\
RD29a-F & tgcaccaggcgtaacaggta & AT5G52310 \\
RD28a-R & taatcggaagacacgacagga & AT5G52310 \\
RAB18-F & cttgcgatttgggatacagc & AT1G43890 \\
RAB18-R & cgtgtctcttcgtgtcacatc & AT1G43890 \\
\hline
\end{tabular}

the delta-delta $\mathrm{Ct}$ method using Act2 as the endogenous control. Each data point was determined in triplicate in each of the three biological replicates and presented as mean $\pm \mathrm{SE}$.

Genetic analysis of T-DNA insertion alleles. Homozygous plant lines for SALK 072421 were confirmed by PCR amplification of total genomic DNA isolated by using CTAB method of Genomic DNA isolation (Weigel and Glazebrook, 2002) left and right genespecific primers, LP (5'-CGAATCTTGAA GCGAAGTCAC $\left.3^{\prime}\right)$, RP (5'-TCCATTGCT AAAATTTCACGC $\left.3^{\prime}\right)$, and LBb1 (5'-GCG TGGACCGCTTGCTGCAACT-3') were obtained from the SIGnAL web site. Homozygous lines were verified by diagnostic PCR using LP and RP primers that did not result in any amplification product whereas heterozygous lines resulted in a PCR product. Furthermore, PCR-using primers LBb1 with both LP and RP primers were used to confirm the TDNA insertion with the homozygous mutants producing a signal amplicon of $\approx 700 \mathrm{bp}$, heterozygous lines producing two amplicons of $\approx 700$ and $900 \mathrm{bp}$, while the homozygous wild types produced a single amplicon of $900 \mathrm{bp}$.

Coexpression analysis. Coexpression analysis was performed using the Arabidopsis Coexpression Tool (ACT; <http://www.
arabidopsis.leeds.ac.uk/ACT>). Statistical analysis of the significance of overrepresentation of Gene Ontology terms in a gene list was performed using the corresponding tool at the ACT web site (Jen et al., 2006; Manfield et al., 2006).

Salt stress tolerance in soil. Seeds of wildtype and pmeil-1 mutant were sown directly in potting soil. Fifteen uniform plants from the wild-type and pmeil-1 populations were selected and grown in the greenhouse using a standard irrigation regime. To assess salt stress tolerance in soil, 3-week-old wild-type and mutant plants were salt-stressed (100 mM) for 4 weeks at weekly intervals.

\section{RESULTS}

Identification of salt-tolerant mutants from the $\mathrm{NaCl}$ phenotype screen. From microarray data collected studying the $\mathrm{NaCl}$ stressalleviating alterations in gene expression, from the organic fraction of the alkaline extract of A. nodosum, we selected the six genes that were maximally downregulated and for which functions of salt resistance had not previously been explained (B. Prithiviraj, unpublished data). Multiple T-DNA insertion lines were selected for each downregulated gene, comprising 
insertions within the promoters, introns, and exons (Table 1); they were the subjected to a functional $\mathrm{NaCl}$ phenotypic screen. To select appropriate T-DNA lines with altered $\mathrm{NaCl}$ phenotypic response, we performed the root gravitropic bending assay comparing the T-DNA lines to controls at 0 and $125 \mathrm{~mm} \mathrm{NaCl}$. Through the root screening, we identified five T-DNA lines, which exhibited enhanced root growth at $125 \mathrm{~mm} \mathrm{NaCl}$ as compared with the Col-0 Arabidopsis controls. Of the $\mathrm{NaCl}$ resistant T-DNA lines, three (Salk_072421, Salk 007858c, and Salk_084836c) were within the putative promoter of At $\lg 62670$ that encodes for a putative PMEI gene. Because all three T-DNA insertions of Atg62670 were found to be resistant, we selected the T-DNA lines for further investigation.

Reverse transcription-polymerase chain reaction analysis of At1g62760 expression reveals that T-DNA mutants are reduced function mutants. To confirm the exact insertion site of T-DNA and to rule out the possibility of chromosomal rearrangements, both T-DNA/genomic DNA junctions of the insertion allele were sequenced. The T-DNA insertion was found $53 \mathrm{bp}$ upstream of the
ATG translational start site within the promoter region of At 1 g62760; similarly, the T-DNA insertion of SALK_007858C was found in the promoter region of At $\lg 62760$. SALK_072421 and SALK_007858C alleles were designated pmeil-1 and pmeil-2, respectively. The T-DNA line Salk_084836c was identified 218 bp upstream of the ATG translational start site and was designated pmei1-3 (Fig. 1). Quantitative real-time PCR analysis was performed to analyze the expression of Atlg62760 in these mutant lines. Transcript levels of Atlg62760 are substantially reduced in pmeil-1, 2, 3 (Fig. 2).

Altered sensitivity of pmeil-1 to $\mathrm{NaCl}$ stress in comparison with wild-type Col-0. There were no visible morphological differences between wild-type Col-0 and pmeil-1 Arabidopsis when grown under optimal conditions. Salt responses were characterized as per Verslues et al. (2006) by transferring 4day-old seedlings to half-strength MS plates containing $\mathrm{NaCl}$ concentrations (i.e., 0, 50, $75,100,125$, and $150 \mathrm{~mm}$ ), measuring the primary root growth at 3 and $7 \mathrm{~d}$ after transfer, and determining the daily growth rate. We observed that the primary root growth rate

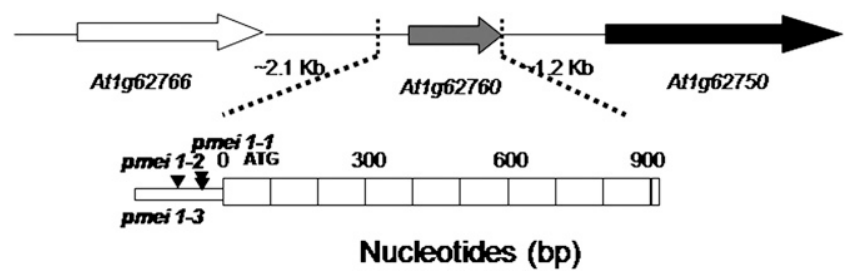

Fig. 1. Physical map of the At $1 g 62760$ locus and T-DNA insertion sites. Broken lines indicate the coding region of the gene with the promoter segment; arrow indicates the predicted transcription direction, Salk_072421 (pmei1-1), Salk_007858c (pmei1-2), and Salk_084836c (pmei1-3). At1g62760 encodes a 939 bp continuous gene lacking introns. The insertion sites are indicated in the promoter regions of Atlg62760v

\section{At1g62760 Pmei1 expresion}

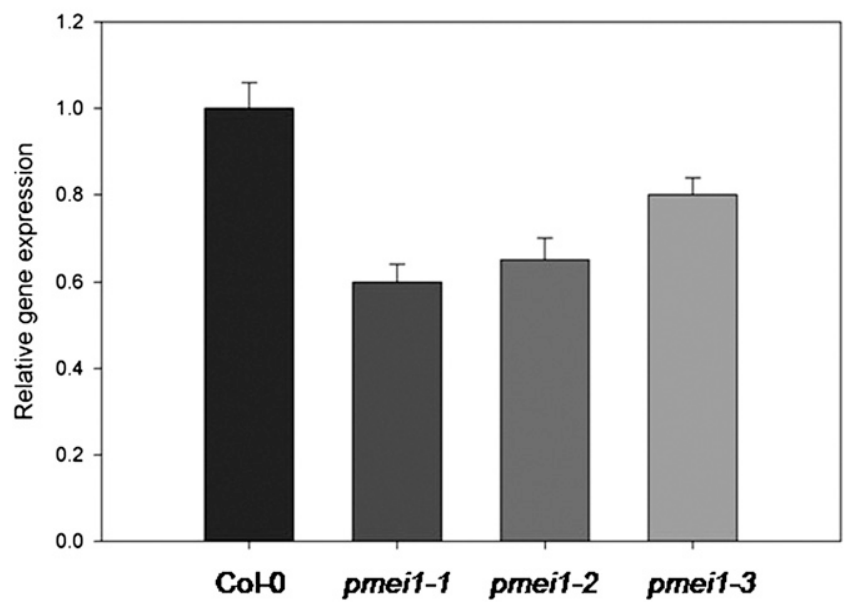

Fig. 2. Quantification of Atlg62760 transcripts in pmei insertional mutants. Quantitative real-time polymerase chain reaction analysis of At lg62760 transcripts in wild-type (Col-0) and mutant (pmei1-1, pmei 1-2, and pmeil-3) lines relative to control. Data represent the means and \pm SE values of three independent biological replicates.

increased in pmeil-1 plants, as compared with controls, when the $\mathrm{NaCl}$ concentration was between 75 and $125 \mathrm{~mm}$. Root growth rates were $\approx 20 \%$ higher in pmeil 1 at $75 \mathrm{~mm}, 100$ $\mathrm{mm}$, and $125 \mathrm{~mm} \mathrm{NaCl}$, respectively (Fig. 3A). However, at $\mathrm{NaCl}$ concentrations greater than $150 \mathrm{~mm}$, there was no increase in pmeil-1 root growth rate (data not shown). Similarly, when the total rosettes of salt-grown plants were measured, pmeil-1 plants accumulated $40 \%$ and $50 \%$ higher fresh weight at 75 and $100 \mathrm{~mm} \mathrm{NaCl}$, respectively, when compared with Col-0 (Fig. 3C).

To determine whether the altered salt stress response in pmeil-1 plants also occurred in plants grown in soil, 2-week-old plants were grown in peat pellets and subjected to salt stress by root irrigation with $100 \mathrm{~mm} \mathrm{NaCl}$ for $\approx 3$ weeks (at weekly intervals). After 3 weeks of root irrigation with $\mathrm{NaCl}$ solution, the Col-0 plants exhibited symptoms of chlorosis and necrosis, whereas the pmeil-1 plants maintained a healthy phenotype (Fig. 4).

Reverse transcription-polymerase chain reaction shows altered salt stress signalling in pmei1-1. To identify possible interactions between known stress adaptation pathways and PMEI, known candidate genes were selected based on their established differential transcriptional regulation in response to salt stress treatment. The transcriptional abundance of these genes was studied in pmeil-1 plants in the presence at 0,50 , and $100 \mathrm{~mm} \mathrm{NaCl}$. $R D 29 A$ and $R A B 18$ were chosen because they are well-characterized salt stress-responsive genes (Jakab et al., 2005) in addition to examining the stress-induced response of PMEII during salt stress. The transcript abundance of $R D 29 A$ was slightly lower in pmeil-1 plants after both 24 and $96 \mathrm{~h}$ of treatment with both 50 and $100 \mathrm{~mm} \mathrm{NaCl}$ compared with Col-0 plants (Fig. 5). There was a slight increase in the basal levels of RD29a transcripts during the unstressed (mock) treatments, increasing by up to $30 \%$ by $96 \mathrm{~h}$ (Fig. 5A), whereas there was no significant difference in the constitutive RAB18 levels (Fig. 5B). Furthermore, there was a substantial decrease in the induced levels of both $R D 29 a$ and $R A B 18$ after treatment of either 50 or 100 $\mathrm{mM} \mathrm{NaCl}$ (Fig. 5A-B). We confirmed that PMEII transcripts levels are increased after salt stress treatment with nearly a 40 -fold increase found $96 \mathrm{~h}$ after treatment with 100 mм $\mathrm{NaCl}$ (Fig. 5C).

Coexpression analysis to reveal the pathway network for Atlg62760. Patterns of coexpression have been used to offer insight into a number of biological processes such as networks of functionally related genes (Wei et al., 2006), convergent gene pairs (Krom and Ramakrishna, 2008), functionality of a single gene in a multigene family (Ho et al., 2007), and also identification of interacting proteins (Fraser et al., 2004). Genes coexpressed and antiexpressed with At $\lg 62760$ were identified using the Arabidopsis Coexpression mining ACT tool (Manfield et al., 2006). The results of this analysis are depicted in Supplementary Tables $1 \mathrm{~A}$ and $1 \mathrm{~B}$. In general, the positively coexpressed genes with annotated function were 

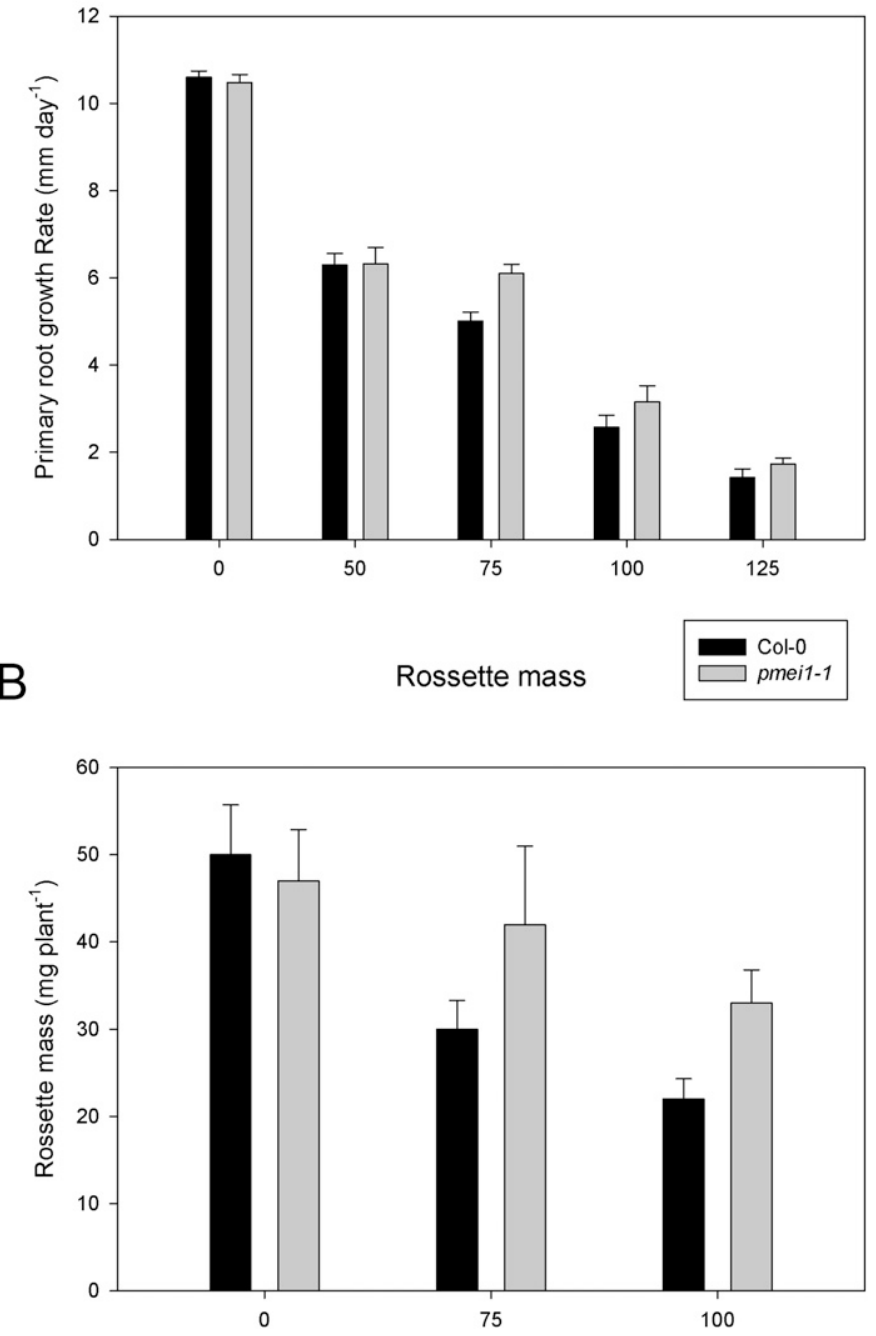

Fig. 3. The mutation in pmei (At 1 g62760) imparts $\mathrm{NaCl}$ tolerance in Arabidopsis. (A) Root length growth rate on salt-containing half-strength Murashige and Skoog (MS) medium. Seedlings were transferred to half-strength MS medium at the indicated $\mathrm{mm}$ concentration of $\mathrm{NaCl}$. Root elongation was determined after 3,5 , and $7 \mathrm{~d}$ and calculated as the elongation rate $\left(\mathrm{mm} \cdot \mathrm{d}^{-1}\right)$. Error bars indicate \pm SE of three independent experiments $(n=30)$. (B) Fresh weight of 4-day-old seedlings growing on indicated $\mathrm{NaCl}$ containing half-strength $\mathrm{MS}$ medium for an additional $15 \mathrm{~d}$. Error bars indicate $\pm \mathrm{SE}$ of two independent experiments $(\mathrm{n}=30)$.

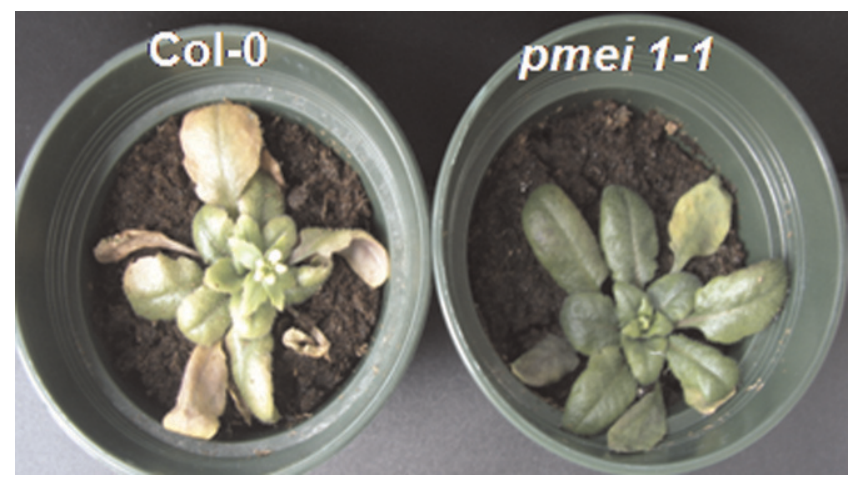

Fig. 4. pmeil-1 mutant Arabidopsis plants are tolerant to salt stress. Representative photograph of Col-0 wild-type and pmeil-1 mutant plants exposed to salt stress $(100 \mathrm{~mm})$ for 4 weeks. Col-0 plants exhibited symptoms of ion toxicity (left) compared with pmeil-1 plants that were relatively tolerant and appeared green (right).

mostly related to senescence, transcription, nucleotide recovery during senescence, and amino acid regeneration; on the other hand, negatively correlated genes were overrepresented in ATP-ase activity (Supplementary Tables 1B and 1C).
Isolating and characterizing genes of agronomic importance are both crucial because the world's agricultural productivity is increasingly affected by abiotic factors, particularly salinity and drought. New methods that rely on function-based screening approaches have been developed to identify novel regulators of stress tolerance (Du et al., 2008; Papdi et al., 2008) in plants. We performed functional screening of six different genes, which were downregulated in Arabidopsis during salt stress by organic extracts of commercial A. nodosum extracts and a potential novel regulator of $\mathrm{NaCl}$ tolerance was identified. In this article, we report the isolation of loss-of-function mutants (pmei1-1) by forward functional screening. At 1 662760 mRNA levels showed an induction in $75 \mathrm{~mm}$ and $100 \mathrm{~mm} \mathrm{NaCl}$ treatments and declined at higher $\mathrm{NaCl}$ concentration (150 $\mathrm{mm}$ ). In this case, pmeil-1 (in Col-0 background) showed a clear phenotype at both 75 and $100 \mathrm{~mm} \mathrm{NaCl}$.

Pectin methylesterase (PME; electrical conductivity 3.1.1.11) is a ubiquitous enzyme in the plant kingdom; however, its role in plant growth and development is not yet clearly understood. PME is reportedly involved in a multitude of physiological processes such as fruit maturation, microsporogenesis and tube pollen growth, cambial cell differentiation, seed germination and hypocotyl elongation, reproductive development, and plant defense (reviewed in Pelloux et al., 2007). Studies suggested that a reduction in PME activity altered cation levels in solanaceous plants (Pilling et al., 2004; Tieman and Handa, 1994). Interestingly, the ion-binding capacities of cell walls from PME-inhibited plants were specifically modified because they preferentially bound more sodium but less potassium. Pilling et al. (2004) also suggested that modifications of ion partitioning were the basis for reduced elongation rates in PMEinhibited plants. PME-catalyzed methanol production might either diffuse or be catabolized into formate, the substrate of formate dehydrogenase, which is upregulated by methanol sprays or environmental stresses such as wounding, cold, and drought in potato leaves (Pelloux et al., 2007). PME-induced methanol production might be more generally involved in plant stress signaling. Interestingly, $R D 29 A$, a stress-induced gene in the salt stress response of Arabidopsis, showed high basal activity in pmeil-1 plants.

The results of anticoexpression analysis revealed an overrepresentation of genes with a functional role involving ion and transmembrane transport aided by ATPases. Plant survival under $\mathrm{NaCl}$ stress depends on activity of membrane transport systems, ATPases, secondary active transporters, and channels (Sze et al., 1999). Increased ATPase-mediated transmembrane proton transport is an early plant cell response to salt stress and is involved in maintaining ionic balance (Ratajczak et al., 1994; Sze et al., 1999). It is possible that ATPase-mediated $\mathrm{H}^{+}$transport may have a role in regulating the transport of $\mathrm{Na}^{+}$, leading to 

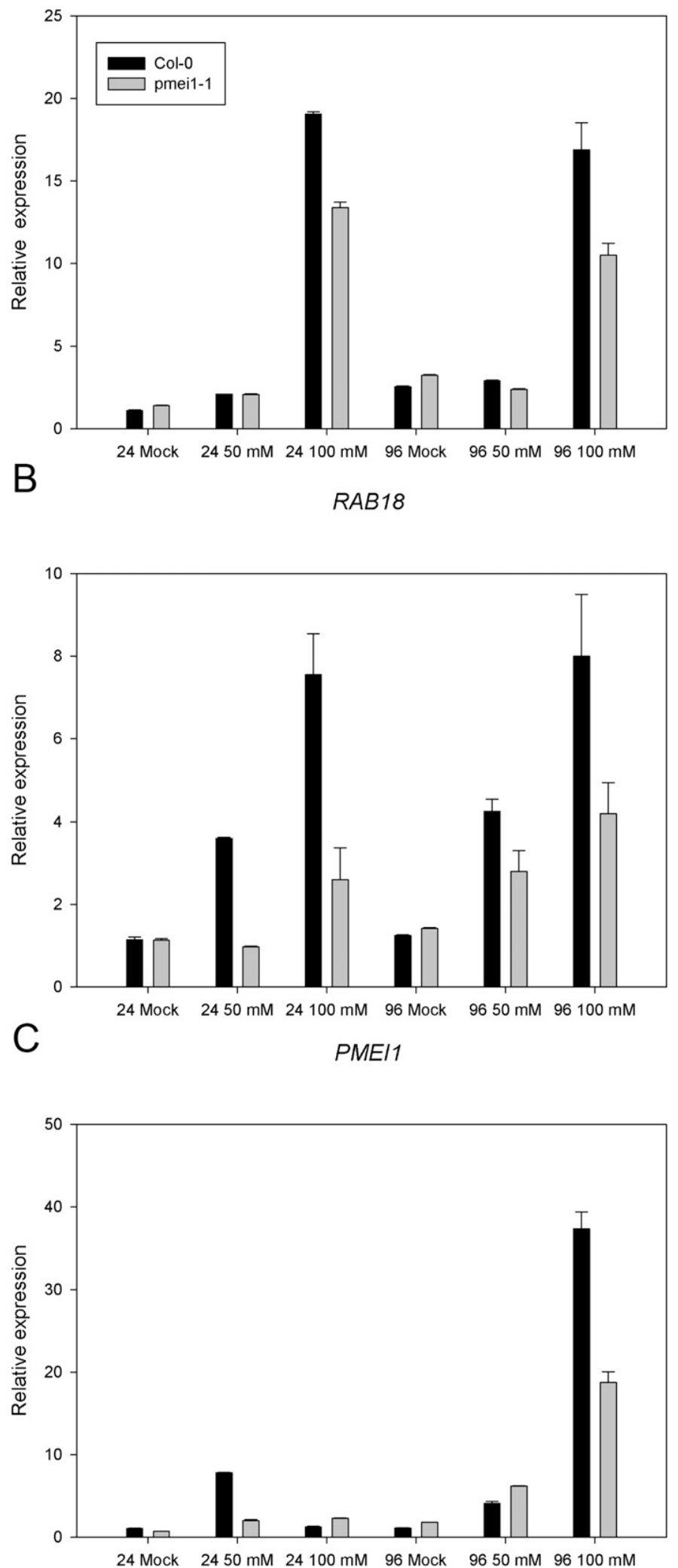

Fig. 5. Expression of stress responsive genes after application of $\mathrm{NaCl}$ in $\mathrm{Col}-0$ and pmei 1-1 plants. Fourweek-old soil-grown Arabidopsis plants were treated with 50 or $100 \mathrm{mM} \mathrm{NaCl}$ for the indicated time of exposure (24 and $96 \mathrm{~h}$ ). The transcript levels were normalized to the Col-0 at $24 \mathrm{~h}$ after mock (water) treatment. Data represent the means and \pm SE values of three independent biological replicates. lower sodium accumulation in the cytosol of pmeil-1 plants. Also, the pmeil-1 mutation did not change the kinetics of the stress gene induction as compared with the Col-0 Arabidopsis. This might suggest independent mechanisms, possibly through ATPase action. Therefore, it appears that $\mathrm{NaCl}$ tolerance in pmeil-1 plants might be, at least it part, affected by the differential regulation of coexpressed genes.

Commercial seaweed extracts are known to induce abiotic stress tolerance in plants (Rayirath et al., 2009; Spann and Little, 2011; Zhang and Ervin, 2004). However, the molecular responses elicited by the extracts and the nature of the chemical components present in those extracts are poorly characterized. Analysis of the molecular mechanisms of action can lead to unraveling novel mechanisms and genes that regulate abiotic stress tolerance in plants in general. By using organic extracts of $A$. nodosum extract that impart salt tolerance in Arabidopsis, we have identified a pmei as a novel, negative regulator of $\mathrm{NaCl}$ tolerance, suggesting that such an approach may potentially be useful in improving plant abiotic stress tolerance.

\section{Literature Cited}

Achard, P., H. Cheng, L. De Grauwe, J. Decat, H. Schoutteten, T. Moritz, D. Van der Straeten, J.R. Peng, and N.P. Harberd. 2006. Integration of plant responses to environmentally activated phytohormonal signals. Science 311:91-94.

Arzani, A. 2008. Improving salinity tolerance in crop plants: A biotechnological view. In Vitro Cell. Dev. Biol. Plant 44:373-383.

Ashraf, M. and N.A. Akram. 2009. Improving salinity tolerance of plants through conventional breeding and genetic engineering: An analytical comparison. Biotechnol. Adv. 27:744-752.

Chomczynski, P. and N. Sacchi. 1987. Single-step method of RNA isolation by acid guanidinium thiocyanate-phenol-chloroform extraction. Anal. Biochem. 162:156-159.

Du, J., Y.P. Huang, J. Xi, M.J. Cao, W.S. Ni, X. Chen, J.K. Zhu, D.J. Oliver, and C.B. Xiang. 2008. Functional gene-mining for salt-tolerance genes with the power of Arabidopsis. Plant J. 56:653-664.

Fraser, H.B., A.E. Hirsh, D.P. Wall, and M.B. Eisen. 2004. Coevolution of gene expression among interacting proteins. Proc. Natl. Acad. Sci. USA 101:9033-9038.

Havlova, M., P.I. Dobrev, V. Motyka, H. Storchova, J. Libus, J. Dobra, J. Malbeck, A. Gaudinova, and R. Vankova. 2008. The role of cytokinins in responses to water deficit in tobacco plants overexpressing trans-zeatin O-glucosyltransferase gene under $35 \mathrm{~S}$ or SAG12 promoters. Plant Cell Environ. 31:341-353.

Ho, L.H.M., E. Giraud, R. Lister, D. ThirkettleWatts, J. Low, R. Clifton, K.A. Howell, C. Carrie, T. Donald, and J. Whelan. 2007. Characterization of the regulatory and expression context of an alternative oxidase gene provides insights into cyanide-insensitive respiration during growth and development. Plant Physiol. 143:1519-1533.

Jakab, G., J. Ton, V. Flors, L. Zimmerli, J.P. Metraux, and B. Mauch-Mani. 2005. Enhancing Arabidopsis salt and drought stress tolerance by chemical priming for its abscisic acid responses. Plant Physiol. 139:267-274.

Jen, C.H., I.W. Manfield, I. Michalopoulos, J.W. Pinney, W.G.T. Willats, P.M. Gilmartin, and 
D.R. Westhead. 2006. The Arabidopsis coexpression tool (ACT): A WWW-based tool and database for microarray-based gene expression analysis. Plant J. 46:336-348.

Kreps, J.A., Y.J. Wu, H.S. Chang, T. Zhu, X. Wang, and J.F. Harper. 2002. Transcriptome changes for Arabidopsis in response to salt, osmotic, and cold stress. Plant Physiol. 130:2129-2141.

Krom, N. and W. Ramakrishna. 2008. Comparative analysis of divergent and convergent gene pairs and their expression patterns in rice, Arabidopsis, and Populus. Plant Physiol. 147:1763-1773.

Kronzucker, H.J. and D.T. Britto. 2011. Sodium transport in plants: A critical review. New Phytol. 189:54-81.

Manfield, I.W., C.H. Jen, J.W. Pinney, I. Michalopoulos, J.R. Bradford, P.M. Gilmartin, and D.R. Westhead. 2006. Arabidopsis Coexpression Tool (ACT): Web server tools for microarray-based gene expression analysis. Nucleic Acids Res. 34:W504-W509.

Nabati, D.A., R.E. Schmidt, and D.J. Parrish. 1994. Alleviation of salinity stress in kentucky bluegrass by plant-growth regulators and iron. Crop Sci. 34:198-202.

Papdi, C., E. Abraham, M.P. Joseph, C. Popescu, C. Koncz, and L. Szabados. 2008. Functional identification of Arabidopsis stress regulatory genes using the controlled cDNA overexpression system. Plant Physiol. 147:528-542.

Pelloux, J., C. Rusterucci, and E.J. Mellerowicz. 2007. New insights into pectin methylesterase structure and function. Trends Plant Sci. 12: 267-277.

Pilling, J., L. Willmitzer, H. Bucking, and J. Fisahn. 2004. Inhibition of a ubiquitously expressed pectin methyl esterase in Solanum tuberosum L. affects plant growth, leaf growth polarity, and ion partitioning. Planta 219:32-40.

Ratajczak, R., J. Richter, and U. Luttge. 1994. Adaptation of the tonoplast V-type H+-ATPase of mesembryanthemum-crystallinum to salt stress, C-3-cam transition and plant-age. Plant Cell Environ. 17:1101-1112.

Rayirath, P., B. Benkel, D.M. Hodges, P. AllanWojtas, S. MacKinnon, A.T. Critchley, and B. Prithiviraj. 2009. Lipophilic components of the brown seaweed, Ascophyllum nodosum, enhance freezing tolerance in Arabidopsis thaliana. Planta 230:135-147.

Rivero, R.M., J. Gimeno, A. Van Deynze, H. Walia, and E. Blumwald. 2010. Enhanced cytokinin synthesis in tobacco plants expressing P-SARK:IPT prevents the degradation of photosynthetic protein complexes during drought. Plant Cell Physiol. 51:1929-1941.

Rivero, R.M., M. Kojima, A. Gepstein, H. Sakakibara, R. Mittler, S. Gepstein, and E. Blumwald. 2007. Delayed leaf senescence induces extreme drought tolerance in a flowering plant. Proc. Natl. Acad. Sci. USA 104:19631-19636.

Seki, M., M. Narusaka, J. Ishida, T. Nanjo, M. Fujita, Y. Oono, A. Kamiya, M. Nakajima, A. Enju, T. Sakurai, M. Satou, K. Akiyama, T. Taji, K. Yamaguchi-Shinozaki, P. Carninci, J. Kawai, Y. Hayashizaki, and K. Shinozaki. 2002. Monitoring the expression profiles of 7000 Arabidopsis genes under drought, cold and high-salinity stresses using a full-length cDNA microarray. Plant J. 31:279-292.

Spann, T.M. and H.A. Little. 2011. Applications of a commercial extract of the brown seaweed Ascophyllum nodosum increases drought tolerance in container-grown 'Hamlin' sweet orange nursery trees. HortScience 46:577-582.

Sreenivasulu, N., S.K. Sopory, and P.B.K. Kishor. 2007. Deciphering the regulatory mechanisms of abiotic stress tolerance in plants by genomic approaches. Gene 388:1-13.

Stamm, P.S., R. Ramamoorthy, and P.P. Kumar. 2011. Feeding the extra billions: Strategies to improve crops and enhance future food security. Plant Biotechnology Reports 5:107-120.

Sze, H., X.H. Li, and M.G. Palmgren. 1999. Energization of plant cell membranes by $\mathrm{H}+$ pumping ATPases: Regulation and biosynthesis. Plant Cell 11:677-689.

Taji, T., M. Seki, M. Satou, T. Sakurai, M. Kobayashi, K. Ishiyama, Y. Narusaka, M. Narusaka, J.K. Zhu, and K. Shinozaki. 2004 Comparative genomics in salt tolerance between Arabidopsis and Arabidopsis-related halophyte salt cress using Arabidopsis microarray. Plant Physiol. 135:1697-1709.
Tieman, D.M. and A.K. Handa. 1994. Reduction in pectin methylesterase activity modifies tissue integrity and cation levels in ripening tomato (Lycopersicon-Esculentum Mill) fruits. Plant Physiol. 106:429-436.

To, J.P.C., J. Deruere, B.B. Maxwell, V.F. Morris, C.E. Hutchison, F.J. Ferreira, G.E. Schaller, and J.J. Kieber. 2007. Cytokinin regulates type-A Arabidopsis response regulator activity and protein stability via twocomponent phosphorelay. Plant Cell 19: 3901-3914.

Turkan, I. and T. Demiral. 2009. Recent developments in understanding salinity tolerance. Environ. Exp. Bot. 67:2-9.

Verslues, P.E., M. Agarwal, S. Katiyar-Agarwal, J.H. Zhu, and J.K. Zhu. 2006. Methods and concepts in quantifying resistance to drought, salt and freezing, abiotic stresses that affect plant water status. Plant J. 45:523-539.

Walia, H., C. Wilson, P. Condamine, X. Liu, A.M. Ismail, L.H. Zeng, S.I. Wanamaker, J. Mandal, J. Xu, X.P. Cui, and T.J. Close. 2005. Comparative transcriptional profiling of two contrasting rice genotypes under salinity stress during the vegetative growth stage. Plant Physiol. 139:822-835.

Wally, O., J. Jayaraj, and Z.K. Punja. 2011. Transgenic vegetables, p. 31-54. In: B. Mou and R. Scorza (eds.). Transgenic horticultural crops. Taylor \& Francis, Boca Raton, FL.

Wei, H., S. Persson, T. Mehta, V. Srinivasasainagendra, L. Chen, G.P. Page, C. Somerville, and A. Loraine. 2006. Transcriptional coordination of the metabolic network in Arabidopsis. Plant Physiology 142: 762-774.

Weigel, D. and J. Glazebrook. 2002. Arabidopsis: A laboratory manual. Cold Spring Harbor Laboratory Press, Cold Spring Harbor, NY.

Zhang, X.Z. and E.H. Ervin. 2004. Cytokinincontaining seaweed and humic acid extracts associated with creeping bentgrass leaf cytokinins and drought resistance. Crop Sci. 44: 1737-1745.

Zhu, J.K. 2002. Salt and drought stress signal transduction in plants. Annu. Rev. Plant Biol. 53:247-273. 